\title{
AVALIAÇÃO DO ARMAZENAMENTO DE PRODUTOS LÁCTEOS COMERCIALIZADOS EM SUPERMERCADOS DE IMPERATRIZ - MA
}

\author{
Karuane Saturnino da Silva Araújo'; Kellytana Almeida Carvalho²; Luana de S. de \\ Azevedo $^{3}$; Raiany Mesquita Santos ${ }^{4}$; Ivaneide de Oliveira Nascimento ${ }^{5}$; Mércia \\ Machado Araújo6.

\begin{abstract}
${ }^{1}$ Mestranda em Ciências da Saúde da Universidade Federal do Tocantins e professora do curso de Agronomia da Universidade Estadual do Maranhão (UEMA). Imperatriz, Maranhão, Brasil. karuane@ hotmail.com

${ }^{2}$ Graduanda do curso de Agronomia da UEMA. Imperatriz, Maranhão, Brasil. kellytana@ hotmail.com ${ }^{3}$ Graduanda do curso de Agronomia da UEMA. Imperatriz, Maranhão, Brasil. luanna_azevedo_19@hotmail.com

${ }^{4}$ Graduanda do curso de Ciências Biológicas da UEMA. Imperatriz, Maranhão, Brasil. raianybio@gmail.com ${ }^{5}$ Professora, Mestre da UEMA. Imperatriz, Maranhão, Brasil. ivaneide_agro@yahoo.com.br

${ }^{6}$ Graduada em Farmácia. machado-mercia@ hotmail.com.
\end{abstract}

\begin{abstract}
RESUMO: Boas práticas de fabricação são procedimentos que devem ser adotados por serviços de alimentação a fim de garantir a qualidade higiênico-sanitária e a conformidade dos alimentos com a legislação sanitária. $\mathrm{O}$ objetivo do presente trabalho foi avaliar as condições de armazenamento de produtos lácteos comercializados em supermercados da cidade de Imperatriz - MA. Foram avaliados 10 supermercados do centro da cidade de Imperatriz e observou-se que cerca de metade dos equipamentos avaliados apresentavam higiene inadequada e péssimo estado de conservação; $60 \%$ dos repositores de produtos lácteos avaliados disseram nunca terem participado de treinamento específico em Boas Práticas de Fabricação de Alimentos (BPF); 50\% disseram ter conhecimento sobre Doenças Veiculadas por Alimentos (DVA), porém $40 \%$ disseram trabalhar mesmo quando estão doentes. A manutenção da qualidade dos produtos lácteos está diretamente ligada a sua forma de armazenamento. Neste sentido é importante aplicar as BPF's também em supermercados da cidade de Imperatriz-MA, dando maior atenção aos repositores de produtos lácteos.
\end{abstract}

PALAVRAS-CHAVE: Alimentos. Armazenagem. Qualidade.

\section{EVALUATION OF STORAGE DAIRY PRODUCTS SOLD IN SUPERMARKETS OF IMPERATRIZ - MA}

\begin{abstract}
Good manufacturing practices are procedures that must be adopted by food services to ensure the sanitary quality of foods and compliance with sanitary regulations. The objective of this study was to evaluate the storage conditions of dairy products commercialized in the city of Imperatriz - MA. We evaluated 10 supermarkets in the city center of Empress and observed that about half of the units evaluated had inadequate hygiene and poor condition, $60 \%$ of stockers dairy assessed say who never attended specific training in Good Food Manufacturing (GMP), 50\% said they had knowledge of Foodborne illness (DVA), but $40 \%$ said work even when ill. Maintaining the quality of dairy products is directly linked to its storage form. In this sense it is important to apply the GMP's (Good Manufacturing Practices for Food) also in supermarkets in the city of Imperatriz-MA, giving greater attention to stockers dairy.
\end{abstract}

KEYWORDS: Food. Warehousing. Quality. 


\title{
EVALUACIÓN DEL ALMACENAMIENTO DE PRODUCTOS LÁCTEOS COMERCIALIZADOS EN LOS SUPERMERCADOS DE IMPERATRIZ - MA
}

\begin{abstract}
RESUMEN: Buenas prácticas de manufactura son los procedimientos que deben ser adoptados por los servicios de alimentación para garantizar la calidad sanitaria de los alimentos y el cumplimiento de los reglamentos sanitarios. El objetivo de este estudio fue evaluar las condiciones de almacenamiento de los productos lácteos comercializados en la ciudad de Imperatriz - MA. Diez supermercados en el centro de la ciudad de Imperatriz se evaluaron y se observó que cerca de la mitad de las unidades evaluadas tenía condiciones higiénicas inadecuadas; $60 \%$ de los repositorios de lácteos evaluado dijo que nunca había participado en una formación específica en Buenas Prácticas de Manufactura para la Alimentación; 50\% dijeron que no tenían conocimiento de las Enfermedades transmitidas por alimentos), pero el $40 \%$ dijo que el trabajo incluso cuando están enfermos. El mantenimiento de la calidad de los productos lácteos está directamente relacionada con su forma de almacenamiento. En este sentido, es importante aplicar Buenas Prácticas de Manufactura para la Alimentación también en los supermercados de la ciudad de Imperatriz-MA, prestando más atención a los repositorios de los productos lácteos.
\end{abstract}

PALABRAS-CLAVE: Alimentos. Almacenamiento. Calidad.

Boas práticas de fabricação (BPF) são procedimentos que devem ser adotados por serviços de alimentação a fim de evitar doenças veiculadas por alimentos (DVA's), garantir a qualidade higiênicosanitária e a conformidade dos alimentos com a legislação sanitária que é regulamentada pela Agência Nacional de Vigilância Sanitária (ANVISA).

A Resolução - RDC no 216, de 16 de setembro de 2004, apresenta o primeiro regulamento nacional sobre Boas Práticas para serviços de alimentação, onde diz que, "A segurança alimentar tem por objetivo garantir que o consumo não cause prejuízo de nenhuma forma ao consumidor". E mais:

As regras vão nortear os comerciantes a procederem de maneira adequada e segura a manipulação, preparo, acondicionamento, armazenamento, transporte e exposição à venda dos alimentos. Essa norma de âmbito federal tem como objetivo a melhoria das condições higiênico-sanitárias dos alimentos preparados em padarias, cantinas, lanchonetes, bufês, confeitarias, restaurantes, comissárias, cozinhas industriais e institucionais (BRASIL, 2004).

A contaminação dos alimentos por microrganismos não pode ser evitada por completo, mas com boas práticas pode ser reduzida, em toda cadeia produtiva. Durante a manipulação pode haver contaminação por condições precárias de higiene de manipuladores, equipamentos, utensílios, ambiente; por más condições das matérias-primas e ingredientes, ou mesmo más práticas de armazenamento dos produtos acabados (ZANDONADI et al., 2007). 
A adequação, a conservação e a higiene das instalações e dos equipamentos, os técnicos responsáveis pelos estabelecimentos, a origem e a qualidade das matérias-primas e o grau de conhecimento e preparo dos manipuladores são imprescindíveis para garantir a segurança dos alimentos (GERMANO; GERMANO, 2008).

O objetivo do trabalho foi avaliar as condições de armazenamento de produtos lácteos comercializados em supermercados do centro da cidade de Imperatriz - MA.

A metodologia utilizada foi a de pesquisa de campo com visitas a 10 supermercados do bairro centro da cidade de Imperatriz - MA para avaliação das condições de armazenamento dos produtos lácteos, bem como a aplicação de questionários aos repositores de produtos lácteos dos respectivos supermercados.
Os itens analisados foram: a higiene dos equipamentos, estado de conservação dos mesmos, apresentação de termostato nas temperaturas exigidas, capacitação dos responsáveis pela reposição em Boas Práticas de Fabricação quando pertinente. Utilizando o software Excel os dados obtidos foram tratados por meio de conversão em porcentagem.

Foram avaliados dois balcões de refrigeração em cada supermercado $(n=20)$ e quanto às condições dos equipamentos de armazenamento de produtos lácteos, 50\% apresentavam higiene inadequada e $40 \%$ dos apresentavam péssimo estado de conservação; porém apenas $20 \%$ dos equipamentos não apresentavam termostato ou indicavam temperatura acima de $10^{\circ} \mathrm{C}$, como pode-se observar no Gráfico 1.

Gráfico 1 - Condições dos balcões de refrigeração de produtos lácteos em supermercados de Imperatriz-MA.

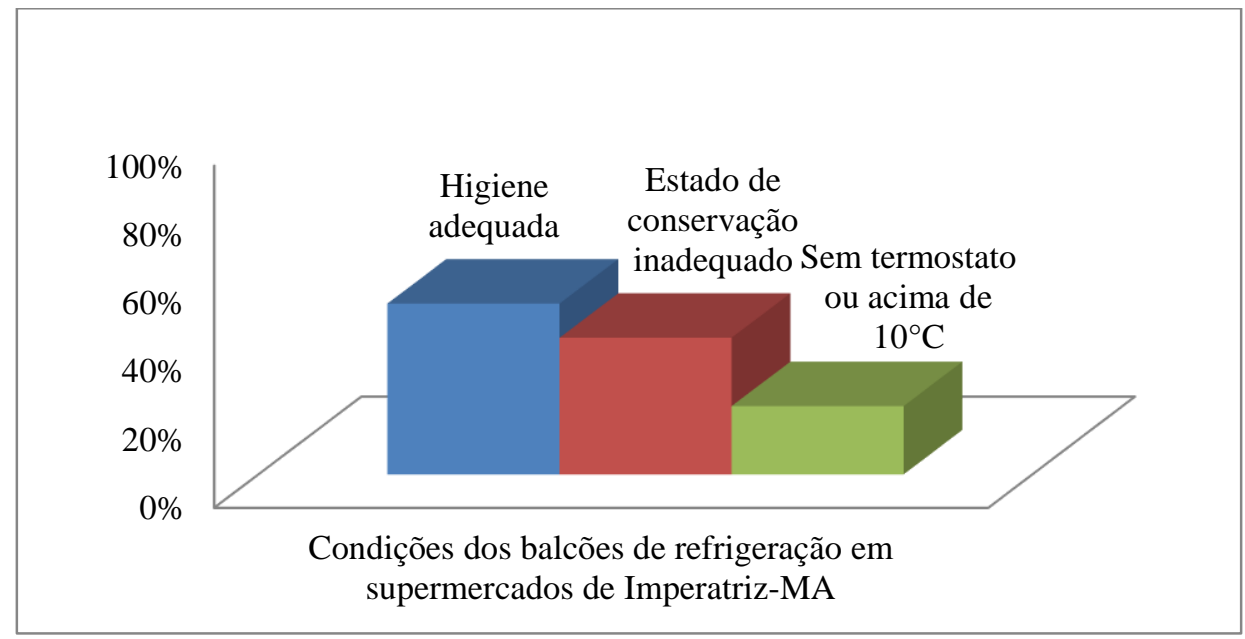


Segundo Macêdo et al. (2000) para manter a qualidade de produtos perecíveis é necessário que as temperaturas dos balcões refrigerados sejam mantidas em faixa aceitável (máximo $10^{\circ} \mathrm{C}$ ). Isso pode ser alcançado com o uso de termostatos aferidos para controle da temperatura, manutenção preventiva dos equipamentos e sua regulagem.

Foram avaliados quatro repositores de produtos lácteos em cada supermercado $(n=40), 60 \%$ disseram nunca terem participado de treinamento específico em
BPF; $50 \%$ disseram ter conhecimento sobre DVA's, porém $40 \%$ disseram trabalhar mesmo quando estão doentes; $70 \%$ disseram que não costumam trocar de jaleco três ou mais vezes por semana, mas 90\% disseram que costumam lavar as mãos antes e durante o processamento; mais de $60 \%$ dos repositores disseram que fazem o uso de EPI's, e que não fazem o uso de acessórios e perfumes no trabalho; todos os repositores entrevistados disseram que mantêm a carteira de saúde atualizada, como observa-se no Gráfico 2.

Gráfico 2 - Práticas dos repositores de produtos lácteos em supermercados de Imperatriz - MA.

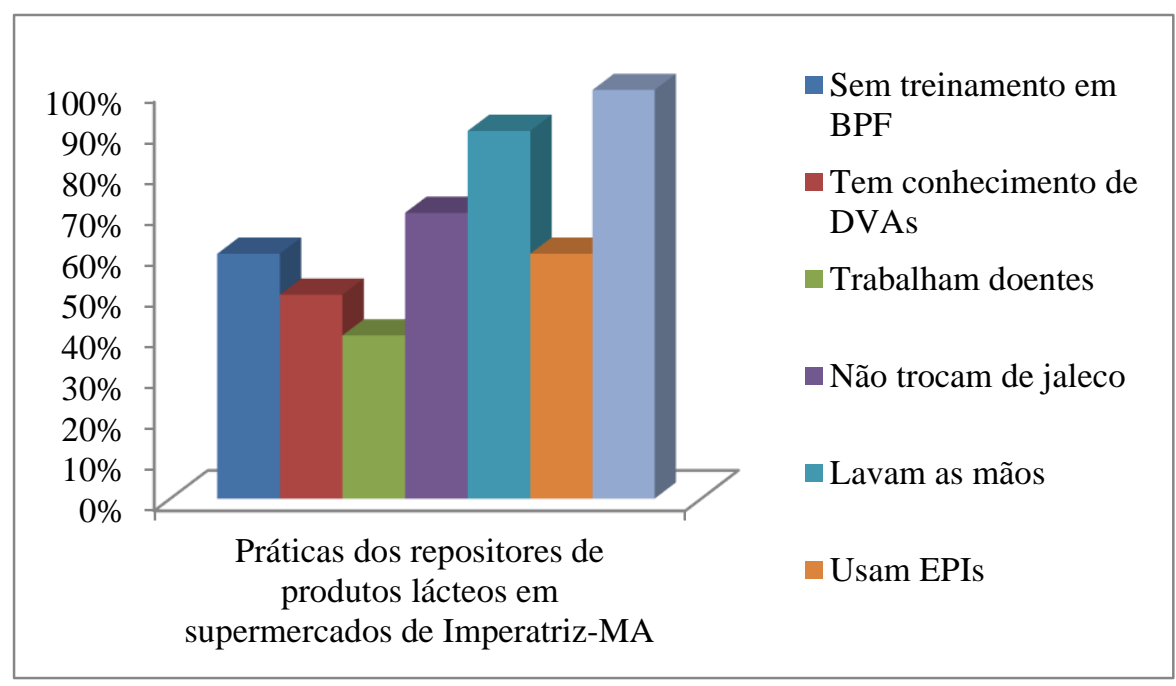

A Resolução no 216 de 15 de setembro de 2004 do Ministério da Saúde (BRASIL, 2004) preconiza:

O controle da saúde dos manipuladores deve ser registrado e realizado de acordo com a legislação específica.

Os manipuladores que apresentarem lesões e ou sintomas de enfermidades que possam comprometer a qualidade higiênico-sanitária dos alimentos devem ser afastados da atividade de preparação de alimentos enquanto persistirem essas condições de saúde.

Os manipuladores devem ter asseio pessoal, apresentando-se com uniformes compatíveis à atividade, conservados e limpos. Os uniformes devem ser trocados, no mínimo, diariamente e usados exclusivamente 
nas dependências internas do estabelecimento. As roupas e os objetos pessoais devem ser guardados em local específico e reservado para esse fim.

Os manipuladores devem lavar cuidadosamente as mãos ao chegar ao trabalho, antes e após manipular alimentos, após qualquer interrupção do serviço, após tocar materiais contaminados, após usar os sanitários e sempre que se fizer necessário. Devem ser afixados cartazes de orientação aos manipuladores sobre a correta lavagem e anti-sepsia das mãos e demais hábitos de higiene, em locais de fácil visualização, inclusive nas instalações sanitárias e lavatórios.

Os manipuladores não devem fumar, falar desnecessariamente, cantar, assobiar, espirrar, cuspir, tossir, comer, manipular dinheiro ou praticar outros atos que possam contaminar o alimento, durante o desempenho das atividades.

Os manipuladores devem usar cabelos presos e protegidos por redes, toucas ou outro acessório apropriado para esse fim, não sendo permitido o uso de barba. As unhas devem estar curtas e sem esmalte ou base. Durante a manipulação, devem ser retirados todos os objetos de adorno pessoal e a maquiagem.

Os manipuladores de alimentos devem ser supervisionados e capacitados periodicamente em higiene pessoal, em manipulação higiênica dos alimentos e em doenças transmitidas por alimentos. A capacitação deve ser comprovada mediante documentação.

Os resultados obtidos nos chamam atenção pelo elevado número de supermercados que não utilizam programas de Boas Práticas de Fabricação exigidos pelo Ministério da Saúde, que implica em mudanças no uso de equipamentos e também em mudanças comportamentais de todas as pessoas envolvidas na distribuição dos alimentos.
Os supermercados que passaram pela avaliação estavam em desacordo com parâmetros exigidos pelo regulamento nacional de Boas Práticas para serviços de alimentação.

\section{REFERÊNCIAS}

BRASIL. Agencia Nacional de Vigilância Sanitária. RDC n ${ }^{\circ} .216,15$ de Setembro de 2004. Dispõe sobre Regulamento Técnico de Boas Práticas para Serviços de Alimentação. Diário oficial da União. Poder Executivo, de 16 de setembro de 2004.

GERMANO, P. M. L.; GERMANO, M. I. S. Higiene e Vigilância Sanitária de Alimentos. São Paulo: Varela, 2008.

MACÊDO, J. A. B., AMORIM, J. M., LIMA, D. C., SILVA, P. M., VAZ, U. P. Avaliação da temperatura de refrigeração nas gôndolas de exposição de derivados lácteos em supermercados da região de Juiz de Fora/MG. Revista Leite e Derivados, n. 53, p.20-30, 2000.

ZANDONADI, R. P. et al. Atitudes de risco do consumidor em restaurantes de auto-serviço. Revista de Nutrição, v. 20, n. 1, p. 19-26, 2007. 